\title{
NACIONALIDADE - DIREITO FUNDAMENTAL, DIREITO PÚBLICO INTERNO E DIREITO INTERNACIONAL
}

\author{
NATIONALITY - FUNDAMENTAL RIGHT, PUBLIC LAW AND INTERNATIONAL LAW
}

Paulo Borba Casella*

\begin{abstract}
Resumo:
A nacionalidade é tema fundamental para o direito, como para o indivíduo enquanto vínculo genuíno com determinada comunidade nacional - mas também para o Direito Constitucional e o Direito Público interno, em relação recíproca de direitos e de obrigações, entre o Estado e o particular; nacionalidade se tornou matéria extensamente regulada, pelo Direito Internacional Público e Privado - de um lado se reconhece que a regulação da nacionalidade é prerrogativa de cada Estado, mas também se reconhece que o indivíduo tem direito a essa condição de 'nacional' e não possa dela ser arbitrariamente privado.

Palavras-chave: Nacionalidade. Nacionalidade da pessoa física. Direito fundamental (direitos do homem). Proteção internacional dos direitos fundamentais. Direito Constitucional. Direito Público. Direito Internacional Público e Direito Internacional Privado (conflito de leis).
\end{abstract}

\begin{abstract}
:
Nationality is a fundamental topic for law, as well as for the individual - as a genuine link with a certain national community - but is also relevant for constitutional and public internal law, in a relation of rights and obligations with reciprocity, between the state and the individual; nationality has turned to be a topic extensively regulated by both public international law and private international law - on the one hand is acknowledged that the regulation of nationality is a prerogative of each state, but also is acknowledged that the individual has the right to the condition of 'national' and may not be arbitrarily deprived of that condition.

Keywords: Nationality. Nationality of the individual. Fundamental right (Human rights). International protection of fundamental rights. Constitutional Law. Public Law. Public International Law and Private International Law (conflict of laws).
\end{abstract}

A nacionalidade é relevante no direito internacional, porque direitos e obrigações internacionais resultam desse vínculo entre o estado e os seus nacionais.

(TREVISANUT, 2012, p. 511).

Professor Titular de Direito Internacional Público e Chefe do Departamento de Direito Internacional e Comparado da Faculdade de Direito da USP. 
1. O tema da nacionalidade pode ser considerado sob diferentes facetas, pelo direito: é relevante enquanto direito fundamental - como dado para definir a identidade e a inserção de cada indivíduo, mas também tem grande relevância para o Direito Público - do serviço militar ao direito de exercer a tributação - e, em razão dos desenvolvimentos ocorridos no último século, não é menos importante e tem várias implicações para o Direito Internacional.

A nacionalidade é primeiro um direito fundamental - segundo a Declaração universal de 1948, art. XV: «todo indivíduo tem direito a uma nacionalidade» e «ninguém pode ser arbitrariamente privado de sua nacionalidade, nem do direito de mudar de nacionalidade» no art. XV.2. Dispositivo semelhante se encontra na Convenção interamericana sobre os direitos e os deveres do homem, em seu art. XX.

2. A nacionalidade é um critério importante para a determinação do estatuto pessoal, no Direito Internacional Privado, assim como o é também o domicílio da pessoa física. $\mathrm{O}$ tema da nacionalidade se tornou objeto de regulação geral pelo Direito Internacional Público, ao mesmo tempo em que continua a ser reconhecida como matéria de competência estatal: cada Estado tem direito de determinar quem são os seus nacionais, e em que condições os estrangeiros ingressam no seu território e nele podem permanecer.

Não mais se aceita a regulação da nacionalidade como campo de regulação discricionária pelo Estado, como antes se entendia, enquanto «domínio reservado» dos distintos direitos públicos internos. Nesse sentido, vejam-se os Protocolos adicionais sobre a aquisição de nacionalidade, nas Convenções de Viena sobre as relações diplomáticas (1961, em vigor em 1964) e consulares (1963, em vigor em 1967).

3. A nacionalidade, enquanto direito fundamental é, como dito, 'direito' essencial para a definição de nossa identidade pessoal - «eu sou armênio, brasileiro, francês ou russo...» e configura um vasto conjunto, mesmo sem considerar a nacionalidade das pessoas jurídicas - o que é matéria suficiente para outro estudo específico, que não cabe empreender aqui, neste momento.

Para estabelecer nosso estatuto legal no plano interno (em Direito Civil ou Administrativo, como em Direito Tributário e outros ramos jurídicos) e, igualmente, no plano do Direito Internacional se posiciona o 'nacional' em relação ao 'estrangeiro' dado crucial para a distinção entre os direitos e o não direito - cuja evidência corrente nos é dada por centenas de milhares de refugiados, sobretudo sírios e iraquianos, empurrados de um país para o outro na Europa.

4. A dimensão da nacionalidade, como direito fundamental, também é demonstrada em alguns casos interamericanos.

A nacionalidade como direito fundamental é afirmada pela Comissão interamericana dos direitos do homem, no caso do Chile, em 1985: «dentre os direitos do homem, depois do direito à vida, a nacionalidade é o mais importante». E também a Corte 
americana dos direitos do homem, no caso das 'disposições relativas à naturalização, na Constituição da Costa Rica', em 1984, declarava ser geralmente admitido que a «nacionalidade é um direito inerente a todo ser humano» e que esse fato deve ser levado em consideração por todos os Estados, quando estes legislam sobre a matéria 'nacionalidade'.

5. Reconhece-se que a nacionalidade permanece uma competência estatal - e isso é afirmado também como princípio de Direito Internacional -, mas este é também um direito fundamental para o indivíduo - o que é igualmente reconhecido internacionalmente.

A nacionalidade é matéria relevante para o Direito Internacional Privado, desde que se aceite inscrever essa temática no âmbito de abrangência da disciplina. Aceitar ou não o tema da nacionalidade no Direito Internacional Privado é exemplo clássico da diferença de tratamento da matéria, entre as posições da doutrina na França e na Inglaterra, sobre a nacionalidade, no Direito Internacional Privado, quer como parte inteira do programa da disciplina (entre os franceses), ou somente como matéria 'introdutória' do Direito Internacional Privado (no caso inglês).

6. No Brasil, a nacionalidade sempre constituiu matéria substancial e formalmente constitucional - e isso se manteve desde a Constituição do Império, até a Constituição vigente. Isso inscreveria a 'nacionalidade' no Direito Público interno e no Direito Constitucional: mas nunca se deixou de estudar também a nacionalidade entre nós, enquanto matéria integrante do Direito Internacional Privado.

Para o Direito Internacional, é a definição da condição de 'nacional' que determinará a aplicação ou não, dentre outros:

- da proteção diplomática (o fato de o indivíduo ser nacional e permanecer nacional de determinado Estado, como condição para possibilitar o exercício da proteção diplomática) - como ilustra o caso Ahmadou Sadio Diallo, entre a República da Guiné e a República Democrática do Congo, na Corte Internacional de Justiça, em 2007; embora o Anteprojeto (Draft Articles) sobre proteção diplomática da Comissão de Direito internacional da ONU, de 2006, em seu art. $8^{\circ}$ diga o contrário, e a prática dos Estados não seja uniforme na matéria;

- da condição jurídica do estrangeiro (para poder ingressar e permanecer, ou não, no território de outro Estado);

- do exercício de direitos políticos (como se prevê, por exemplo, na Convenção sobre igualdade de direitos civis e políticos, entre Brasil e Portugal, ou entre os países da CPLP - a Comunidade de países de língua portuguesa);

- da lei aplicável (ao lado do domicílio); e

- da jurisdição (ou também da lex loci delicti commissi - o lugar onde o ilícito foi cometido). 
7. A nacionalidade, para o Direito Internacional Público, configura um dos elementos básicos para a existência e o reconhecimento do Estado: para cada Estado, o 'povo' é um dos três elementos de base para a sua existência e a sua inserção internacional, assim como o 'território' e o 'governo', os três dados indispensáveis, para assegurar a existência e o reconhecimento do Estado, enquanto sujeito de Direito Internacional.

Segundo a nacionalidade, se estabelecem as relações pessoais com os 'elementos de estraneidade' (o que pode se estender do estatuto pessoal imposto à competência do Estado para tributar ou não aquele indivíduo, até vasta gama de escolhas interpessoais).

8. Cada Estado determina quem são os seus nacionais, como se adquire ou se perde determinada nacionalidade e, inversamente, em relação aos estrangeiros aqueles que, por definição, não são os nacionais daquele Estado.

Existem limites, segundo o Direito Internacional, para cada Estado, na determinação dessa condição - quem são os nacionais de cada Estado: ou seja, os Estados devem observar parâmetros jurídicos internacionais, quer para 'reconhecer' ou 'recusar' a nacionalidade - e isso não pode ser feito arbitrariamente, quer para indivíduos, como para coletividades inteiras, tal como ocorreu no passado, com as nefandas 'naturalizações em massa'.

9. Podemos afirmar que ocorreu 'internacionalização' no tratamento do tema da nacionalidade. A antiga Corte permanente de justiça internacional (“CPJI"), no caso dos «decretos de nacionalidade na Tunísia e no Marrocos», em 1923 (série B, n. 4, par. 24) considerava o Estado do Direito Internacional naquela altura e via a nacionalidade, originariamente, como um domínio reservado dos Estados (domaine réservé des états), mas não excluía que a nacionalidade pudesse se tornar igualmente matéria de regulação pelo Direito Internacional.

Na mesma linha de raciocínio, ainda a CPJI, no parecer sobre «a aquisição da nacionalidade polonesa» (série 7, n. 7, par. 16). E, desde então, a nacionalidade se tornou efetivamente matéria extensamente regulada por normas de Direito Internacional.

10. A efetividade da nacionalidade na jurisprudência internacional pode ser avaliada pela ulterior atuação da sucessora da CPJI, a atual Corte Internacional de Justiça, quando esta considera, como se deu na questão entre o Liechtenstein e a Guatemala - no caso Nottebohm (1955): a existência de um 'vínculo efetivo' (lien effectif) entre o cidadão e o Estado, como condição para a determinação da nacionalidade.

Sim, mas somente quando existir escolha possível entre duas nacionalidades. O que não se dava no caso, porquanto o sr. Nottebohm não mais tinha a sua nacionalidade alemã de origem, e nunca tinha adquirido a nacionalidade guatemalteca, e apesar disso a Corte não admitiu a 'efetividade' da nacionalidade do Liechtenstein pelo indivíduo 
em questão. Por esse motivo, nesse caso, a melhor parte a ser estudada são os votos divergentes, para considerar o mérito da matéria em exame.

11. Para exame da jurisprudência internacional em matéria de nacionalidade também se deve atentar para precedentes emanados da Corte Permanente de Arbitragem ("CPA") e da Corte Europeia de Direitos Humanos ("CEDH"). Da CPA, lembre-se o caso Canevaro (1961), entre a Itália e o Peru - onde também se tratou de questão da efetividade da nacionalidade.

Na CEDH, o caso Micheletti c. Delegación del Gobierno en Cantabria (1992), tratou do caso de cidadão argentino e italiano, que pretendia fixar domicílio permanente na Espanha. E, em relação à mesma questão da 'efetividade' da nacionalidade, a CEDH afirma que não se pode excluir o vínculo nacional com um dos países europeus. Pode-se dizer que o caso Micheletti recoloca em questão a 'efetividade' para dar lugar à nacionalidade como um 'direito' do indivíduo.

12. A nacionalidade, ainda segundo a CEDH, no caso Rottmann c. Freistaat Bayern (2010, caso C-135/08), mesmo se os Estados têm os poderes para determinar as condições para a aquisição e a perda da nacionalidade, e os Estados podem levar em conta a sua competência nesse domínio, o tema foi reconhecido como princípio de Direito Internacional.

Segundo a evolução da regulação da matéria na U.E., cada Estado pode ver se reduzir o campo de aplicação dos seus poderes, em matéria de nacionalidade, na medida em que existem direitos e deveres estabelecidos pela U.E., que podem inclusive ser objeto de decisão judicial (o papel do ‘judicial review’ como elemento de consolidação institucional e conceitual do processo de integração) à luz do direito da U.E.

13. Ainda a respeito da nacionalidade, na $\mathrm{CEDH}$, no caso Kuric c. Eslovênia (2010) (CEDH App. 26828/06, par. 353) - segundo a Corte «não existe direito à aquisição ou à manutenção de determinada nacionalidade, dentre os direitos e liberdades previstos pela Convenção e os seus Protocolos».

Desse modo, a Corte «não exclui que negativa arbitrária de [reconhecimento de] cidadania poderia, em determinadas circunstâncias, suscitar uma questão, nos termos do art. 8 da Convenção, em razão do impacto de tal denegação sobre a vida do indivíduo».

14. A questão da efetividade da nacionalidade, a contrário senso, ainda na CEDH, no caso Beldjoudi c. França (App. 12083/86) decidiu proteger um indivíduo que seria deportado para um país, com o qual ele não tinha vínculos, apesar de sua nacionalidade argelina. O Sr. Beldjoudi tinha nascido e sempre viveu na França, tendo se casado com uma cidadã francesa, mas perdera a sua nacionalidade francesa, porque quando menor, na altura da independência da Argélia, seus pais tinham deixado de fazer por ele a declaração correspondente de opção pela nacionalidade francesa. Depois de ter 
sofrido condenação criminal, o Estado francês pretendia expulsar Beldjoudi do território francês.

A CEDH considerou que Beldjoudi não tinha vínculos com a Argélia, apesar de sua nacionalidade, e que seria excessivo expulsá-lo da França. Aqui se tratou de aplicação de variante da teoria do vínculo efetivo, para proteger a nacionalidade de fato, diante da nacionalidade formal, como direito fundamental desse indivíduo, face ao Estado francês.

15. Pode-se situar a nacionalidade, entre denegação e aquisição. Pode-se observar que não somente a denegação de nacionalidade, mas também, inversamente, a outorga de determinada nacionalidade, contra a vontade de uma pessoa, pode suscitar questões concernentes a garantia de direitos fundamentais, na vida pessoal. Daí se pode deduzir a exclusão das naturalizações em massa, em caso de sucessão de Estado - estas podem ser contrárias ao princípio de não intervenção, enquanto meio de coerção, exercido por um Estado, em relação a outro.

Nesse sentido, se inscrevem os Princípios (Draft Articles) da Comissão das Nações Unidas para o Direito Internacional (“CDI”) sobre a «nacionalidade das pessoas físicas, em caso de sucessão de Estado».

16. A respeito da relação entre nacionalidade e casamento, o Direito Internacional evoluiu no sentido da exclusão da mudança automática de nacionalidade, em razão do casamento, do fim do casamento ou de mudança de nacionalidade do marido, durante a vigência do casamento.

A evolução nessa matéria se fez desde os arts. 10 e 11 da Convenção sobre certas questões concernentes aos conflitos de leis em matéria de nacionalidade (1930, em vigor em 1937). No sentido dessa evolução, apontem-se não somente os artigos primeiro e $9^{\circ}$, da Convenção para a eliminação de todas as formas de discriminação contra a mulher (1979, em vigor em 1981), como também o art. 5. d (iii) da Convenção internacional para a eliminação de todas as formas de discriminação racial (1966, em vigor em 1969).

17. A nacionalidade, como matéria regulada pelo Direito Internacional Público, mostra considerável evolução, desde a regulação contida na Convenção da Haia em matéria de nacionalidade, de 1930, até a Convenção Europeia em matéria de nacionalidade, em 1997 (em vigor em 2000).

Na medida em que a nacionalidade se tornou uma 'questão europeia', proporcionalmente se reduz a capacidade dos Estados membros em regular diversamente a matéria, conforme o art. 20 do Tratado sobre o funcionamento da União Europeia ("TFUE", de 2007, em vigor em 2009), para a 'cidadania da União', segundo a nacionalidade de cada um dos Estados membros.

18. O reverso da questão da nacionalidade é a ausência desta, ou a apatridia. Este é igualmente grave problema, que tem de ser evitado. Nesse sentido, já se colocava 
a Convenção para a redução dos casos de apatridia (1961, em vigor em 1975), até a Convenção para evitar a apatridia em casos de sucessão de Estado (2006, em vigor em 2009).

19. No Direito brasileiro, desde a Constituição do Império em 1824, a nacionalidade é material e formalmente considerada como matéria constitucional. Da mesma forma, na Constituição da República, em 1891, como em todas as que se sucederam, até a presente Constituição de 1988, notadamente desde a mudança do texto do art. 12, em matéria de nacionalidade, em 1994.

Mesmo sempre tendo sido adotado, pelo Direito Constitucional brasileiro, o local de nascimento (jus soli) como o critério de base, em um país de imigração, para a determinação da nacionalidade, sempre se reservou também espaço para a filiação (jus sanguinis) como critério para se reconhecer a nacionalidade brasileira de origem, e a esses dois princípios, é preciso acrescer o domicílio (ius domicilii), como elemento subsidiário, para a determinação da nacionalidade.

20. Para se avaliar o Estado atual da matéria 'nacionalidade', no Direito Constitucional brasileiro, deve-se levar em conta que a Constituição de 1988, com as mudanças introduzidas na redação do art. 12, em 1994, sem acarretar riscos de perda da nacionalidade brasileira, doravante aceita mais claramente o «reconhecimento de nacionalidade de origem» e chega mesmo a admitir que um pedido de aquisição de nacionalidade estrangeira não acarrete a perda da nacionalidade brasileira de origem, quanto tal se fizer necessário para a ver assegurado o direito de residência, em país estrangeiro, que faça tal exigência, sem acarretar a perda da nacionalidade brasileira de origem.

Houve considerável 'flexibilização' das normas anteriormente vigentes. O que se pode, contudo, questionar é o caso de nacional brasileiro, que adquira outra nacionalidade, e voluntariamente se inscreva no serviço militar de outro Estado. Nesse caso, entendo que se poderia cogitar de perda da nacionalidade brasileira de origem, por rompimento do ‘vínculo genuíno’ entre o cidadão e o seu Estado de origem.

21. Em conclusão, pode-se considerar ter ocorrido substancial progresso da regulação em matéria de nacionalidade. Notadamente no caso do Direito brasileiro, que passou de tratamento anteriormente bastante restritivo, para o atual quadro de considerável flexibilidade. Inclusive no tocante ao reconhecimento de nacionalidade estrangeira de origem e de aceitação de pedido voluntário de naturalização estrangeira, no caso de brasileiros residentes no exterior.

Pode-se considerar terem ocorrido substanciais progressos nessa matéria, desde o momento em que os Estados temiam que casos de dupla ou de plurinacionalidade poderiam enfraquecer os vínculos entre o Estado e o indivíduo. Doravante parece ser admitida a percepção - como se nota tanto no contexto da U.E. como igualmente no 
sistema interamericano - da nacionalidade como domínio onde pode haver lugar para considerável extensão da autonomia da vontade do indivíduo - sem relegar a importância do vínculo da nacionalidade, também para o Estado.

22. A nacionalidade permanece um vínculo importante entre o indivíduo e o Estado, do qual este é nacional, mas esse vínculo é recíproco, e não mais pode ser visto somente como uma prerrogativa do Estado, sem contar o indivíduo. Nas questões concernentes à nacionalidade, enquanto direito fundamental, internacionalmente protegido, o indivíduo se torna elemento central - como ademais há de ser, em todo o direito, interno ou internacional.

A 'internacionalização' do regime jurídico da nacionalidade é tendência marcante, no sentido de acrescer ao vínculo entre o Estado e o seu nacional a dimensão de direito fundamental e a proteção internacional desse direito. Convenções em matéria de proteção de direitos humanos, como a Convenção interamericana, em seu art. 20, já mencionado, colocam parâmetros a serem observados pelos Estados, ao conceder a nacionalidade a determinado indivíduo.

O mesmo se verifica em instrumentos internacionais como a Convenção internacional para a eliminação de todas as formas de discriminação racial, em seu art. 5, d (iii), ou na Convenção para a eliminação de todas as formas de discriminação contra as mulheres, em seu art. $9^{\circ}$. O Direito Internacional progressivamente limita a discricionariedade dos Estados em matéria de atribuição e de denegação de nacionalidade da pessoa física.

São Paulo, abril de 2016.

Referências

ACCIOLY, Hildebrando; SILVA, Geraldo Eulálio do Nascimento e; CASELLA, Paulo Borba. Manual de direito internacional público. 22. ed. São Paulo: Saraiva, 2016.

AMERASINGHE, Chittharanjan Felix. Diplomatic Protection. Oxford: Oxford University Press, 2008.

CAHALI, Yussef Said. Estatuto do estrangeiro. São Paulo: Saraiva, 1983.

CASTRO Y BRAVO, F. de. La nationalité, la double nationalité et la supra-nationalité. Recueil des Cours, l'Académie de Droit International de la Haye, Haye, t. 102, p. 519-634, 1961.

DE FROUVILLE, Olivier. Affaire Ahmadou Sadio Diallo (Republique de Guinée contre République démocratique du Congo). Exceptions préliminaires: le roman inachevé de la protection diplomatique Annuaire Français de Droit International, Paris, v. 53, p. 291-327, 2007. 
DOLINGER, Jacob. Nottebohm revisited. In: CASELLA, P. B. (Coord.). Dimensão internacional do direito: estudos em homenagem a G. E. do Nascimento e Silva. São Paulo: LTr, 2000. p. 141-186.

DÖRR, Oliver. Nationality. The Max Planck encyclopedia of public international law. Oxford: Oxford University Press, 2012. v. 7, p. 496-510.

MANCINI, Pasquale Stanislao. A nacionalidade como fundamento do direito das gentes. Preleção ao curso de direito internacional e marítimo, proferida na Real Universidade de Turim, no dia 22 de janeiro de 1851. In: MANCINI, Pasquale Stanislao. Direito internacional. Tradução de Ciro Mioranza. Ijuí: Ed. Unijuí, 2003. p. 31-86.

MARINHO, Ilmar Penna. Tratado sôbre a nacionalidade. Rio de Janeiro: Departamento de Imprensa Nacional, 1957.

REZEK, José Francisco. Le droit international de la nationalité. Recueil des Cours, l'Académie de Droit International de la Haye, Haye, t. 198, p. 333-400, 1984.

RODAS, João Grandino. A nacionalidade da pessoa física. São Paulo: Revista dos Tribunais, 1990. SPIRO, Peter J. Multiple nationality. In: WOLFRUM, Rudiger. (Ed.) The Max Planck encyclopedia of public international law. Oxford: Oxford University Press, 2012. v. 7, p. 416-421.

STRENGER, Irineu. Direito internacional privado. 4. ed. aum. e atual. São Paulo: LTr, 2000.

TIBURCIO, Carmen. Temas de direito internacional. Rio de Janeiro: Renovar, 2006.

TREVISANUT, Seline. Nationality cases before international courts and tribunals. In: WOLFRUM, Rudiger. (Ed.) The Max Planck encyclopedia of public international law. Oxford: Oxford University Press, 2012. v. 7, p. 510-517. 
